\title{
Samarco disaster and health policies in Espírito Santo
}

\author{
Desastre da Samarco e políticas de saúde no Espírito Santo: ações \\ aquém do SUS?
}

Frederico Viana Machado', Monika Weronika Dowbor ${ }^{\mathbf{2}}$, gor Amaral2

DOI: $10.1590 / 0103-11042020$ E210I

\begin{abstract}
The present study sought to understand the mitigating actions proposed in response to the impact caused by the rupture of the Samarco dam in the city of Mariana, Minas Gerais. As part of a larger study, this section focuses on public health policies and the cities of Colatina and Linhares, in the state of Espírito Santo. Through qualitative methods, the political-administrative arrangement involving the company Samarco, the Interfederative Committee (CIF), the Renova Foundation and public authorities was investigated, questioning the role of the actors in the production of compensatory and remedial measures. Document analysis was used, especially the reports available on the Renova Foundation website (from March 2016 to May 2018), and seven semi-structured interviews with leading actors in the two cities studied. The analysis was guided by the theoretical scope of the public policy cycle. A clearly structured top-down political-administrative structure was identified, with an emphasis on the formulation of policies at the expense of service delivery and little articulation between public actors and civil society in the search for solutions to health problems.
\end{abstract}

KEYWORDS Disaster planning. Public health. Public policy.

RESUMO O presente estudo buscou compreender as ações mitigadoras propostas como resposta ao impacto provocado pelo rompimento da barragem da Samarco na cidade de Mariana, Minas Gerais. Como parte de um estudo maior, este recorte enfoca as políticas públicas de saúde e as cidades de Colatina e Linhares, no estado do Espírito Santo. Por meio de métodos qualitativos, investigaram-se o arranjo politico-administrativo que envolve a empresa Samarco, o Comitê Interfederativo (CIF), a Fundação Renova e os poderes públicos, interrogando sobre o papel dos atores na produção de medidas compensatórias e reparatórias. Foram utilizadas a análise de documentos, sobretudo, os relatórios disponíveis no site da Fundação Renova (de março de 2016 a maio de 2018), e sete entrevistas semiestruturadas com atores de referência nas duas cidades estudadas. $A$ análise foi orientada pelo escopo teórico do ciclo de políticas públicas. Identificou-se uma estrutura político-administrativa formulada de forma nitidamente top down, com ênfase na etapa da formulação de políticas em detrimento da entrega de serviços e com pouca articulação entre os atores públicos e da sociedade civil na busca de solução de problemas de saúde.

1 Universidade Federal do Rio Grande do Sul (UFRGS) - Porto Alegre (RS), Brasil. fredvma@yahoo.com

2 Universidade do Vale do Rio dos Sinos (Unisinos) São Leopoldo (RS), Brasil.

PALAVRAS-CHAVE Planejamento em desastres. Saúde pública. Política pública. 


\section{Introduction}

This article analyzes the mitigating actions proposed and carried out in response to the impact caused by the rupture of the Samarco dam in the city of Mariana, state of Minas Gerais. As part of a larger study, this section focuses on public health policies and the cities of Colatina and Linhares, in the state of Espírito Santo. Through qualitative methods, we investigated the political-administrative arrangement involving the Samarco company, the Interfederative Committee (CIF), the Renova Foundation and the public authorities, questioning the actions of these actors in the production of measures aimed at repairing the damage caused to the health of the affected population, from formulation to implementation, as well as their interactions with the municipal health sector.

The relation between public health and emergencies and disasters finds technical and political support in international benchmarks, such as the Essential Public Health Functions (Fesp), systematized by the Pan American Health Organization in 2002; the International Health Regulations at the 2005 World Health Organization; the Hyogo Framework for Action in the 2005 International Strategy for Disaster Reduction; and, recently, the Sendai Framework of 2015. The latter deepens these relations by expanding the notion of 'disaster' and recognizing the role of health policies in reducing risks and coping with emergencies and disasters. However, Londe ${ }^{1}$ reviews the Civil Defense Secretariat's manuals on emergency or public calamity and argues that "impacts on public health are, generally, undervalued and classified as 'secondary disasters'"'1(538). Freitas ${ }^{2}$ points out that disasters are little researched in the scope of Brazilian collective health.

The impacts of disasters on public health are discussed with support from the Pan American Health Organization ${ }^{\mathbf{3}, 4}$. The effects of disasters on public health occur in the short term (mortality and serious injuries), medium (increase in diseases) and long term (depressive processes and psychosocial damage) ${ }^{2}$. Although in the case of cities in the state of Espírito Santo, the purpose of this analysis, public health facilities were not damaged by the disaster, the impacts on public health were many, medium and long-term.

The medium and long-term effects require, or should require, the elaboration of health policies and services to attend, prevent and mitigate the diverse and complex incidences of illnesses, but also psychosocial processes, such as depression, loss of social identity, collective and cultural development by those affected ${ }^{1-4}$. The mitigation of human damage is expected to reduce the severity of systemic processes that feed psychosocially, affecting the development and local economy, autonomy and organizational processes of communities, limiting access to resources and conditioning the possibilities of recovery and reconstruction.

In the case of the disaster caused by Samarco, a new institutional arrangement was set up, which consists of providing 'compensatory and reparatory programs' by a private entity specially created for this purpose, the Renova Foundation, according to the Terms of Transaction and Conduct Adjustment (TTAC) ${ }^{5}$. The Term is a legal agreement signed between the Executive, the Judiciary and the company that caused the disaster and provides for a series of programs and measures necessary to compensate and recover the resulting socio-economic and socio-environmental damages. The conduct of these actions, according to the TTCA, will be inspected and supervised by the government ${ }^{5}$. In this way, the answers to public problems are, or should be, given through an institutional arrangement that articulates the different spheres of the public authority to CIF - an organ that brings together states, municipalities and the Federal Executive Branch with the power to inspect 
and sanction of mitigating policies - and the Renova Foundation, created specifically to meet the demands caused by the disaster ${ }^{6}$.

To analyze the result of this strategy for public health policies in the cities of Colatina and Linhares, we ask: what is considered public health policy by the proposed institutional arrangement? What is the role of each of the actors in the formulation and implementation of planned and executed actions? Consequently, it is necessary to highlight the health problems faced and the proposed actions, as well as the effectiveness of these actions. Finally, the accountability capacity of this system is considered, since listening to those affected is fundamental both in formulation and implementation and, above all, in evaluation. In other words, what is the capacity of this arrangement to be monitored and evaluated continuously and effectively?

\section{Methodology}

We opted for a qualitative methodological design, which associated document analysis and semi-structured interviews $\mathbf{~}^{\mathbf{7}, \mathbf{8}}$. The survey raised documents, focusing on Renova's reports, published on this organization's website (www.fundacaorenova. org), in the period between March 2016, the date of signing the TTAC, and May 2018, the date of collection. In Renova's reports', all proposals and actions directly related to health and the cities studied were selected. Thirty five actions were identified, understood here as the public expression of the foundation about its conceptions, ways of acting and relating.

These actions were classified into two broad categories subdivided into subcategories (chart 1). The first is 'Type of Action', which refers to the action repertoire employed by the Foundation and was created from the native categories, that is, those used by Renova in its reports, namely: a) Preparations for the implementation; b) Implementation; c) Bureaucraticadministrative procedure; d) Institutional Procedure; e) Meeting. The second category, 'Action content', was built based on the concept of public policy cycle that distinguishes five stages: agenda-setting, alternatives specification, decision making, implementation and evaluation ${ }^{\mathbf{1 0}}$, adapted to the case and the material (reports accountability) investigated. While applying this analysis screen, we sought to understand the stages in the production of health actions, the general scope of which had been defined by the TTAC. The subcategories in this case are: a) Alternatives specification; b) Search for Partnership; c) Hiring of third-parties; d) Diagnosis; e) Delivery of products and services; f) Accountability. We also map the actors with whom Renova had a relationship in each of the actions. These data were submitted to frequency and content analysis. 
Chart 1. Definitions of analysis categories used in the analysis of the Renova reports

\begin{tabular}{|c|c|}
\hline Type of action & Classification criteria \\
\hline $\begin{array}{l}\text { Preparations for the implementa- } \\
\text { tion }\end{array}$ & $\begin{array}{l}\text { Action prior to the delivery of products and services as such, here understood as } \\
\text { implementation. }\end{array}$ \\
\hline Implementation & Delivery action of programme-related products and services. \\
\hline $\begin{array}{l}\text { Bureaucratic/administrative pro- } \\
\text { cedure }\end{array}$ & Action carried out by Renova that is part of its internal processes as a Foundation. \\
\hline Institutional Procedure & $\begin{array}{l}\text { Action that Renova performs according to the institutional order of the governance } \\
\text { arrangement established in the TTAC. }\end{array}$ \\
\hline Meeting & $\begin{array}{l}\text { Renova action in which the Foundation relates to civil society actors and communi- } \\
\text { ties (meeting for workshop and presentation of work teams for the community, } \\
\text { meeting for the purpose of listening/dialogue with a view to the decision-making } \\
\text { process) }\end{array}$ \\
\hline \multicolumn{2}{|c|}{ Classification of reports according to the content of the action } \\
\hline Action content & Classification criteria \\
\hline Alternatives Specification & Process involving discussion and debate on actions, programs and policies. \\
\hline Search for Partnerships & Action that seeks to attract actors to work together with Renova.. \\
\hline Hiring of third-parties & $\begin{array}{l}\text { Action for hiring and signing contracts with companies, civil society organizations } \\
\text { or government. }\end{array}$ \\
\hline Diagnosis & $\begin{array}{l}\text { Action aimed at the elaboration of data. Search for evidence to establish a causal } \\
\text { link between the disaster and the problem found. Survey of data and demands, } \\
\text { report or study carried out, technical visits carried out in order to collect data and } \\
\text { facts to support technical opinions. }\end{array}$ \\
\hline Delivery of products and services & Action aimed at delivering a product or service to the end user. \\
\hline Accountability & $\begin{array}{l}\text { Action to provide information and deliver plans and projects when Renova was } \\
\text { required to perform such action. }\end{array}$ \\
\hline
\end{tabular}

Source: Own elaboration.

As a complementary method and in order to understand how Renova's actions were related to the public health system, seven semistructured interviews were conducted, three with managers from the Health Departments of Linhares and Colatina, an interview with a councilor from the Municipal Health Council of Linhares and three interviews with technicians from the State Institute of Environment who also participate in the Technical Chambers of the CIF/Brazilian Institute of Environment and Renewable Natural Resources (Ibama) (we will not present further details on the characterization to safeguard the anonymity of the interviewees). The interview script focused on the relationship between health policies and the effects of the disaster, exploring the participation of each of the actors involved and the actions implemented.

\section{The health of those affected after the dam burst}

The environmental crime caused by the Samarco/Vale/BHP disaster was one of the worst environmental tragedies in history, whose recovery will take decades. Although the number of deaths was low compared to the 2019 Brumadinho disaster, the health impacts of those affected were many:

a) compromised services for the provision of food and drinking water; $b$ ) regulation of the 
climate (destruction of more than a thousand hectares of vegetation cover) and water cycles (contributing to floods in the rainy periods), contributing to changes in the vector and disease host cycles (dengue, chikungunya and zika, in addition to other diseases such as schistosomiasis, Chagas disease, leishmaniasis, which may appear months after the initial period of the disaster); c) venomous animals, which also had their habitats completely altered or destroyed; d) respiratory diseases and contamination of organisms with the transformation of waste sludge into a great source of dust and particulate matter (containing iron oxide, silica and organic matter, in addition to the hypothesis of other metals such as aluminum and manganese) inhaled by people (14); e) psychosocial and mental health impacts, resulting from the compromise of cultural heritage and the loss of the sense of place, as well as the feeling of insecurity and fear of violence for those displaced to shelters or temporary homes, contributing to future chronic diseases, like cardiovascular ones. No less serious were also the impacts on the Krenak Indians, who had their lifestyles, culture and religion affected by the disaster ${ }^{\mathbf{1 1}(27)}$.

As an important long-term effect, Wanderley et al.12 present studies that relate the presence of heavy metals in rivers to the increase in chronic diseases and point out the need for follow-up and monitoring by public policies. Neves et al. ${ }^{\mathbf{1 3}}$ highlight the effects on the population's mental health, such as the occurrence of post-traumatic stress in $82 \%$ of children and adolescents, suicide risk of $16.4 \%$ in those affected, prevalence of depression in $28.9 \%$ and generalized anxiety disorder in $32 \%$ of respondents. It is noted that the health effects of the affected population will not be resolved in the short term and will be felt by individuals and communities for a long time. As Freitas et al. ${ }^{\mathbf{1 4}}$ argue, for collective health, it is important to consider the "emergence of new health problems and needs over time, so that they mobilize almost any public health structure"14(1).
Thus, changes in the population's epidemiological profile and in the social health needs caused by the disaster will demand responses from the public authorities in public health policies at the local and regional level, considering, above all, medium and long-term effects. At the very least, primary care and health surveillance systems must be strengthened, working in an articulated and intersectoral manner with other public policy fronts, given the complexity and intensity of the problems generated. The psychosocial context demands actions to promote health and popular education that value and reinforce community ties. Specialized care services must be expanded to deal with increased demand, but also to prepare for active searches and collective interventions. Public policies must articulate actions to meet health demands, preventing the medium and long term consequences ${ }^{\mathbf{1 4}}$. It is important that information on Public Health is integrated with Civil and Environmental Defense ${ }^{\mathbf{1 5}}$.

These prerogatives of the public authorities should be considered and supported by the Renova Foundation and by the institutional arrangement created to follow-up, monitor and evaluate its performance as an executor of 'compensatory and reparatory programs'.

\section{Results and discussion}

\section{Description and problematization of the institutional arrangement}

Since the moment of the disaster, the elaboration of mitigating measures has gone through the double formulation stage, the first being the elaboration of proposals by technicians who made up an interministerial group (between 2015 and the beginning of 2016) and whose result was incorporated by TTAC. The second stage concerns the preparation of proposals by Renova. The third 
stage takes place inside the CIF, responsible for approving or not the proposals prepared by Renova, always in consultation with the Technical Chambers that make up the bodies responsible for the inspection of Renova for each action front.

The first stage involved several bodies of direct and indirect administration of the Federal Government, under the coordination of the Republic's Chief of Staff: Attorney General's Office (AGU), Ministry of Social Development and Fight against Hunger (MDS), Ministry of Agrarian Development (MDA), Ministry of Agriculture, Livestock and Food Supply (Mapa), Ministry of Justice (MJ), Government Secretariat of the Presidency of the Republic (Segov), Ministry of Health $(\mathrm{MH})$, Ministry of Education (MEC), Ministry of Culture (MinC), National Foundation for Indigenous People (Funai) and Ibama. By the Public Power, representatives of the Governments of the States of Minas Gerais (Department of Regional Development, Urban Planning and Metropolitan Management) and of the State of Espírito Santo (Department of Sanitation, Housing and Urban Development) also participated.

From this interministerial meeting, several programs emerged that, later on, served as the basis for the approval of the TTAC. The document explains the guidelines defined by the meeting, with the participation of the $\mathrm{MH}$, and directs the following determinations to Samarco/Renova Foundation:

Support program for the physical and mental health of the impacted population: support for the elaboration of a protocol for monitoring the health of the exposed population; support to Mariana and Barra Longa in the execution of local health plans; development of an epidemiological and toxicological study, from Mariana to the mouth of the Rio Doce, in order to assess risks resulting from the collapse; adoption of mitigating measures to guarantee the health of the population in case of risk identification ${ }^{5(134)}$.
The TTAC was signed on March 2, 2016 and ratified on May 5, 2016 by the Federal Court. It took just three months from the date of the filing of the public civil action (November 30, 2015) until the signing of the TTAC. This was the time that negotiations on the terms foreseen in the TTAC lasted. In view of the fact that this period would not be sufficient to accurately characterize the real extent of the environmental and socioeconomic damage caused by the disaster, the signatory parties chose to write a TTAC with generic and indeterminate clauses. It is observed that support for the "execution of local health plans' was restricted to Mariana and Barra Longa, and other measures should be adopted in 'case of risk identification', which depends on studies and assessments that may take time and do not have a stipulated deadline for completion.

Notwithstanding the lack of prior diagnosis capable of providing reliable information that would support the detailed formulation of the remedial, remediation, compensation and indemnity measures to be adopted, the TTAC established limits for the allocation of resources to certain categories of actions. In addition to establishing that reparatory socioeconomic programs would have priority over other programs, TTAC established an annual fixed amount for expenditure on compensatory measures. In the logic established in the TTAC, it will not be possible to allocate resources in excess of $\mathrm{R} \$ 240$ million per year for compensatory actions, even if these are necessary. The term also determined that the company has 15 years to carry out all mitigation programs.

In the period covered by the survey (March 2016 to May 2018), TTAC is in force, and the CIF system is operating. The Technical Chamber (TC) of Health, in charge of supervising Renova's actions in this sector, was created only on May 9, 2017. On December 12, 2017, the Renova Foundation handed over a Report that aims to formalize the deliveries of the definition phase of 
the Physical and Mental Health Support Program for the Impacted Population according to the Term of Transaction and Conduct Adjustment (TTAC - clauses 106 to 112)'. In it, Renova indicates what it has already accomplished - talks about the focus on emergency actions - and describes the planning for the following years. About three months later (March 23, 2018), the coordinator of the TC of Health sends a letter from the Executive Secretary of the CIF pointing out that the Renova Report is not referring to the Unified Health System (SUS) and its standards, and several other criticisms. On May 10, TC rejected the report, pointing out several shortcomings, including lack of details on plans, documents and results. This is the interaction context between the Foundation and the CIF system in which the actions carried out by Renova are inserted, to be analyzed below.

\section{How are recovery policies produced and implemented?}

As already explained, the effects of the disaster caused by the rupture of a dam belonging to the Samarco company, in the city of Mariana (MG), would be repaired and/ or compensated through programs carried out by the Renova Foundation, controlled by the companies and by the new intergovernmental body: the CIF of which the sectoral Technical Committees are members. This institutional arrangement, or governance model, was created to handle the production of decisions, the search for alternatives, the implementation of concrete actions to compensate or repair the damage caused by the disaster as well as its inspection. Although it is controversial to call these actions 'public policies', disaster started to occupy the State's agenda through the TTAC, being treated as a public problem and the object of actions for reparation and compensation that entered or should enter the implementation agenda of private and public actors. The latter were tasked not only with monitoring and inspecting, but also with approving action plans. In addition, what is more important, for concrete actions, thousands of people named 'affected' were and are waiting. Citizens and, therefore, bearers of rights.

Thus, the set of actions that we cover can be analyzed through the lens of the public policy cycle from a multicentric perspective ${ }^{10}$. The work of Renova and CIF are part of the structure for implementing health actions to remedy problems arising from the disaster. Of the six stages of the cycle, the first two (problem identification and agenda-setting) were defined after the dam broke with the signing of the TTAC. The other four phases (alternatives specification, decision, implementation, evaluation and monitoring) will continue to tension the institutional arrangement, focusing on Renova as a focus, as TTAC has not sufficiently specified the actions to be implemented and only requires that the Foundation elaborate and submit its action plans for the approval and evaluation of the CIF. It is necessary to emphasize that the cycle and its stages cannot be seen in a mechanical and linear way. The stages can be repeated within the same cycle, overlap or the cycle itself can occur more than once within the same policy, but this flow of cascading processes does not prevent highlighting the relevant actors and the characteristics of each stage ${ }^{10}$.

The analysis of the alternatives specification, when solutions are elaborated so that, based on technical and political criteria, decisions are made ${ }^{16,17}$, helps us to identify who presented, elaborated or participated in the solutions presented by Renova. Were the municipal health departments of the cities studied here (Linhares and Colatina) part of the elaboration of the solutions? Have those affected been consulted? How long did the decision-making process take? If the decision stage is characterized by being restricted to the responsible decision makers, here it is worth asking whether, outside the CIF, the 
companies' boards played a veto role, delaying the process. The implementation stage, in turn, is far from the mere execution of orders from above. Or it could be exactly that, but with all the imperfections already detected in the literature ${ }^{\mathbf{1 8}}$. The authors who deal with the implementation also indicate that, in its execution, different configurations of actors may appear among the public, private, for-profit and non-profit; and these configurations will have different effects in terms of effectiveness in the delivery of shares ${ }^{\mathbf{1 9}}$. This synthesis of particular features of the implementation stage leads us to question the composition of the implementation structure and the effectiveness of the delivery of products and services.

\section{Production of health actions after the dam breaking}

The TTAC, from clause 106 to 113, designates the Renova Foundation to develop activities to support the physical and mental health of those affected and to prepare an epidemiological and toxicological study to identify the retrospective, current and prospective epidemiological and health profile of the residents of Mariana up to the mouth of the Rio Doce, in order to assess risks and correlations resulting from the disruption ${ }^{5}$. For health actions, Renova has R $\$ 128$ million to be invested over ten years from the date of the disaster. The analysis of the activities in Renova's reports related to 'health' in the first 30 months after the break shows that the alternatives specification, that is, search for solutions to the identified problems, corresponded to $40 \%$ of the total actions (table 1). Secondly, Renova reports its actions as elaboration of diagnoses that covered $31.4 \%$ of the total. An example of this type of 'health action' is Renova's 'technical visit' to the leaders of the Regência and Povoação communities in order to gather data and facts to support technical advice. Thirdly, the Foundation spent its time looking for partnerships and hiring third-parties, which together account for almost $23 \%$. The category of service delivery to users was mentioned only once. If the elaboration of diagnoses corresponds to that expected by the assignment contained in the TTAC, the part that determined support for physical and mental health was clearly in the definition phase.

Table 1. Content of actions developed by Renova in health (03/2016 to 05/2018)

\begin{tabular}{lrr}
\hline Actions content & Frequency & Percent \\
\hline Alternatives Specification & 14 & 40.0 \\
Search for Partnerships & 4 & 11.4 \\
Hiring of third-parties & 4 & 11.4 \\
Diagnostic & 11 & 31.4 \\
Accountability & 2 & 5.7 \\
Delivery of products and services & 1 & 2.8 \\
Total & 36 & 100 \\
\hline
\end{tabular}

Source: Own elaboration based on the reports of the Renova Foundation? 
We analyzed the same actions through the filter of the form, that is, trying to understand how the Foundation is organized, how it proceeds and how it acts to execute the planned programs (table 2). The forms corroborate the previous analysis that indicates the predominance of the alternatives specification in terms of content when showing that Renova promoted at that time with quite intensity the meetings ( 13 of the total of 36), among which are those with communities affected. This data can be interpreted in two different ways. If, on the one hand, it shows the existence of these contacts, it is clear that the Foundation did not elaborate any specific form in its repertoire of action to name the systematic relations with those affected and make them a specific line of action. On the other hand, given the complexity of the actions to be carried out and the networks of relationships that the company had to build to execute the health mitigation program, the need for a continuous flow of approach and deliberation with other actors, whether social or state, is evident. Among other more frequent forms, it is worth mentioning Renova's involvement in an equitable way in bureaucratic/ administrative procedures that concern the Foundation's own functioning and in relation to the requirements of the CIF that appear in the category of institutional procedure, 11 and 9 , respectively.

Table 2. Renova's repertoire of action related to health (03/2016 to 05/2018)

\begin{tabular}{lrr}
\hline Type of action & Frequency & Percentage \\
\hline Implementation & 1 & 2.7 \\
Preparations for the implementation & 2 & 5.5 \\
Bureaucratic/administrative procedure & 11 & 30.5 \\
Institutional Procedure & 9 & 25 \\
Meeting & 13 & 36.3 \\
Total & 36 & 100 \\
\hline
\end{tabular}

Source: Own elaboration based on the reports of the Renova Foundation? 9

The third filter of analysis involves the question about the actors with whom Renova related. In view of the previous data, it is not surprising that $70 \%$ of its actions took place with State actors, primarily CIF, under the legal force of TTAC. This is because the entity has no autonomy to make decisions and often needs to report its movements to the body. In addition to the CIF, Renova has been associated with other state actors, among them, even if only occasionally, with municipal health departments. Even though it is stipulated in the TTAC that the society is to be heard and the actions are to be built in a participatory manner, the Foundation's reports do not indicate this movement. Organized civil society entities are those that occupy the last place compared to institutional actors, in terms of number of times they were mentioned in the reports.

To briefly summarize, the data set presented here gives greater strength to the argument that the Foundation, between March 2016 and May 2018, was still in the alternative formulation stage and far from showing effectiveness in its recovery actions with regard to health. Given the scarcity of effective mitigating policies, since the analysis of the Renova Foundation's monthly reports, we interviewed public agents, who work in the 
cities of Colatina and Linhares. The purpose of this piece of the research was, once again, to understand how the actors involved in the process, Renova, Ibama, the state and municipalities, articulated themselves in the search for answers to the damages caused by the mud in the health of the affected population.

Public agents declare dissatisfaction with the institutional arrangement created to mitigate the losses of the mud, either with reports critical to the execution of the bureaucratic process determined by the TTAC, or due to the difficulties of access to and inspection of the Renova Foundation. A health worker says that, until March 2019, the implementation of public policies had been done only by the municipal government:

To this day, only to ourselves. Renova only appears here to apply questionnaires. State government helps with more bureaucratic issues, so, in the end, everything ends with the City Hall. With the attendants, with the doctor of the $B H U$, with health workers, in short, with the tip of the system. We do what we can, but it is extremely complicated.

A social worker also reports that the municipality has been the biggest driver of policies, without counting on the help of other actors:

Within our human and financial limits, we do everything we can. Everything! However, our range of actions is limited and, moreover, is already worn out. We turn to the other departments, the mayor, the people here. State Government assists in what is agreed, nothing extra. Renova? It runs away from us. It created a foundation to not fulfill the role of helping people.

The disbelief of the servers is not restricted to the Foundation, but also to the institutions created from the TTAC (the CIF and the TCs). According to a nurse, "they do not produce the expected answers". In the same sense, the social worker argues that the new arrangement is unproductive: "We fight, fight, fight, it is time to carry out the actions, inside the same CIF, and nothing comes of it. It's all difficult".

In addition to the relationship problems of the new institutional arrangement, there are also disputes of interest. A health worker, representative of the health secretariat of one of the municipalities at CIF, expresses this problem:

There is a lot of interest within this whole scheme, political and financial interest. If they solved the problem of lack of transparency, it would help a lot.

Although the diagnosis was one of the actions to be implemented by Renova, the interviewees linked to the municipal health sector are unaware of which diseases are caused by the disaster and which are not, and argue that this is a topic of disagreement and conflict between the actors involved. At the same time, the construction of the institutional arrangement of CIF with its Chambers shows a certain slowness in the coming and going between documents produced and issued between Renova and the supervisory bodies.

In both cities, both the Public Power and the company had not yet carried out adequate studies on the impact on the health of those affected in the cities of the state of Espírito Santo. Without the elaboration of tests that demonstrate the appearance of diseases, there is no way to produce and establish effective public policies. This already demonstrates the 'health' perspective associated with the absence of disease, which is insufficient to mitigate the long-term effects. At the same time, two nurses and a social worker were emphatic in pointing out the increase in health problems, both physical and psychological, identified in the services provided.

In the analyzed period and data, we did not identify any interaction with the health public facilities, guidelines and policies formulated by SUS. The health policies instituted and consolidated in the territories, which were overloaded and did not receive contributions for qualification or enhancement, were not 
mentioned in Renova's reports. Little affinity of the propositions with the institutional framework of SUS is identified, and there was no reinforcement, expansion or qualification of the local health network to serve the population.

This seemed to be an important data for our questions in the introduction, since the public health policies are ignored, as well as the actors who execute them. We identified that Renova relates preferentially to state actors, but not to actors who are at the forefront of public health policies. The greater frequency of actions, such as 'meetings' and bureaucratic procedures, questions the effectiveness of what has been accomplished for the health of those affected, at the same time that it leads us to identify a little participative perspective.

The lack of connections between the planned actions and public health policies leads us to criticize the underlying conception of public policy present in the institutional framework that produced the analyzed arrangement. According to the TTAC, the Foundation will provide technical support to assist the city halls and the actions to be carried out by the Foundation itself, but there was no provision for articulation between primary care and health surveillance, nor with Civil and Environmental Defense or social assistance, to think about the medium and long term effects. How do private actors respond to public problems without negotiating with established health authorities? A concept in which the agents executing the mitigating actions are outsourced, without being the target of arrangements that promote participation and social control, reduce the system's accountability capacity, as revealed by some interviewees. The instances of social control already established, such as the Municipal Health Councils, do not even participate in the discussions within the scope of the arrangement studied here, while our interviewees complain about the lack of transparency in the process.
In summary, it is noted that the institutional arrangement has generated a political-administrative structure formulated in a clearly top down manner, which reinforced the stage of formulating policies at the expense of implementation and without articulating the actors involved, whether from SUS or from the civil society.

\section{Final considerations}

The data analyzed lead us to consider that the health actions to mitigate the problems caused by the disaster in the region of Linhares and Colatina are incipient and disconnected from the specific needs of the health field, especially the medium and long term effects, which are related directly to social inequalities and the constitution of communities. Three years after the dam breaking, the municipal health secretariats had no reliable data on the impacts on health and no articulated action plan. The low capacity for execution and the non-existent role of participatory bodies to produce any effect in the decision-making process were weak points in the proposed arrangement.

It is alleged that the level of generality is one of the reasons for the low effectiveness of the actions specified in the TTAC and because CIF is not propositional, but reactive. In the case of health, it is added that one of the reasons for the low effectiveness is the non-inclusion of SUS as part of the proposed actions; which could have its infrastructure enhanced, qualified and/or expanded, or at least be considered in the articulation with other actors, avoiding waste of resources and synergy in actions.

The absence of SUS and measures to strengthen the structure in operation in the health network can be seen as a political culture that devalues public policies, as it does not consider the accumulation and the resolutive capacity of this system as relevant for facing the consequences of the disaster. On the other hand, the interviewees linked 
to the health departments indicate that there has been an overload in the health system due to the increased demand for care after the disaster.

It is important to highlight that the problems generated by this model would be resolved by the doctrinal and organizational principles of SUS. The doctrinal principles universality, integrality and equity - would add to this arrangement social sensitivity and strategic scope to address the impact of inequalities, social health needs and the complexity of health-disease processes. The organizing principles - regionalization and hierarchy, decentralization, single command and social participation - would alert to the importance of the organization of services at levels of complexity, planning based on epidemiological criteria (articulating primary care and health surveillance) that adequately characterize the population assisted. This points to the articulation between the existing services and the agreement between actors to guarantee resources and technical and political capacity for the effective execution of health actions. Social participation, a constitutive principle of SUS, brings together the actors involved, qualifies health practices and increases the capacity for accountability. All of these principles are related to critical problems of the analyzed model.

From June 2018 on, one month after the deadline for data collection for this research, therefore, the institutional arrangement and agreements have undergone important changes aimed at remedying the problems identified even by this investigation. In June, the governance TTAC was signed, which created formats for the effective and constant participation of the affected communities in the CIF-Renova institutional arrangement. The TC of Health issued Note 4, in which it stated that Renova should establish a subprogram to support and strengthen the SUS; and, in October 2018, it published yet another note stipulating that the affected municipalities should develop Health Action Plans to be supported and strengthened by the Foundation. Both notes were approved by CIF. As a result, local diagnostics and prognoses would be prepared by municipal health departments and their communities. The process progressed little, with only one municipality presenting the Plan until June 2019. Thus, the Public Defender's Office and the Public Ministry of Espírito Santo held a meeting to commit the municipalities to such plans; and, together with the Federal Public Defender's Office and the Federal Public Ministry, issued a recommendation to municipalities that had not yet positioned themselves.

Through these actions, the gradual incorporation of SUS, its guidelines and principles can be noticed, as well as its agents into the institutional arrangement. The effects of repairing the damage caused by the rupture of the Samarco dam to health are yet to be researched, but it is clear that the first design that separated SUS and the affected communities from the programs developed at TTAC and to be implemented by Renova was not effective at least with regard to health actions in Espírito Santo in the first 30 months after the dam breaking. Arrangements made up of actors with sectorial and management skills permeated by the voice of the community appear to be quite promising so that social rights can be fulfilled in time and over time.

\section{Collaborators}

Machado FV (0000-0002-8884-1124)*, Dowbor MW (0000-0002-1845-046X)*, Amaral I (0000-0001-7884-7808)* also contributed to the elaboration of the manuscript. 


\section{References}

1. Londe LR, Marchezini V, Conceição R, et al. Impactos de desastres socioambientais em saúde pública. R. bras. Est. Pop. 2015; 32(3):537-562.

2. Freitas CM, Silva DRX, Sena ARM, et al. Desastres naturais e saúde: uma análise da situação do Brasil. Ciênc. Saúde Colet. [internet]. 2014 [acesso em 2019 set 29]; 19(9):3645-3656. Disponível em: http:// dx.doi.org/10.1590/1413-81232014199.00732014.

3. Organização Pan-Americana da Saúde; Ministério da Saúde. Desastres naturais e saúde no Brasil. Brasília, DF: Opas; Ministério da Saúde; 2014 (Série Desenvolvimento Sustentável e Saúde. v. 2).

4. Organização Pan-Americana da Saúde. Protección de las nuevas instalaciones de salud frente a desastres naturales: guía para la promoción de la mitigación de desastres. Washington, DC: Opas; Banco Mundial; 2003.

5. Instituto Brasileiro de Meio Ambiente e dos Recursos Naturais Renováveis; Instituto Chico Mendes de Conservação da Biodiversidade. Termo de Transação e de Ajustamento de Conduta. Brasília, DF: ICMBio; 2016.

6. Instituto Brasileiro de Meio Ambiente e dos Recursos Naturais Renováveis. Regimento Interno do Comitê Interfederativo. Brasília, DF: Ibama; 2016.

7. Creswell J. Research Design: Qualitative, Quantitative, and Mixed Methods Approaches. London: SAGE; 2003.

8. Minayo MCS. O desafio do conhecimento: pesquisa qualitativa em saúde. 8. ed. São Paulo; Rio de Janeiro: Hucitec; Abrasco; 2004.

9. Fundação Renova. Relatórios mensais [internet]. 2016-2018. [acesso em 2019 jun 23]. Disponível em: https://www.fundacaorenova.org/wp-content/uploads.

10. Secchi L. Políticas Públicas: conceitos, esquemas de análise, casos práticos. São Paulo: Cengage Learning; 2013.

11. Freitas CM, Silva MA, Menezes FC. O desastre na barragem de mineração da Samarco: fratura exposta dos limites do Brasil na redução de risco de desastres. Cienc. Cult. [internet]. 2016 [acesso em 2019 set 29]; 68(3):25-30. Disponível em: http:// dx.doi.org/10.21800/2317-66602016000300010.

12. Wanderley LJ, Mansur MS, Milanez B, et al. Desastre da Samarco/Vale/BHP no Vale do Rio Doce: aspectos econômicos, políticos e socio ambientais. Cienc. Cult. [internet]. 2016 [acesso em 2019 set 29]; 68(3):30-35. Disponível em: http://dx.doi. org/10.21800/2317-66602016000300011.

13. Neves MGL, Roque M, Freitas AA, et al. PRISMMA. Pesquisa sobre a saúde mental das famílias atingidas pelo rompimento da barragem de Fundão em Mariana. Belo Horizonte: Corpus; 2018.

14. Freitas CM, Barcellos C, Asmus CIRF, et al. Da Samarco em Mariana à Vale em Brumadinho: desastres em barragens de mineração e Saúde Coletiva. Cad. Saúde Pública [internet]. 2019 [acesso em 2019 set 29]; 35(5):e00052519. Disponível em: http://dx.doi.org/10.1590/0102-311x00052519.

15. Sobral A, Freitas CM, Andrade EV, et al. Desastres naturais - sistemas de informação e vigilância: uma revisão da literatura. Epidemiol. Serv. Saúde. 2010; 19(4):389-402.

16. Kingdon JW. Agendas, alternatives and public policies. New York: Harper Collins; 1995.

17. Capella ACN. Formulação: o processo de defini- 
ção de alternativas. In: Capella ACN. Formulação de Políticas. Brasília, DF: ENAP; 2018. p. 71-108.

18. Hogwood B, Gunn L. Why "perfect implementation" is unattainable. The policy process. reader. 1993; (2):217-25.

19. Hjern B, Porter DO. Implementation structures: A new unit of administrative analysis. In: Holzner
B, Knorr KD, Strasser H. Realizing social science knowledge. Heidelberg: Physica, Heidelberg; 1983.

p. 265-277.

Received on 09/30/2019

Approved on 04/08/2020

Conflict of interests: non-existent

Financial support: Coordination for the Improvement of Higher

Education Personnel (Capes), Notice 'Research Networks for the Recovery of the Rio Doce Basin' and National Council for Scientific and Technological Development (CNPq) 